\section{Post-earthquake Repositioning in a High-Value Heritage Context}

Journal of Planning Education and Research $1-13$

(C) The Author(s) 2020

Article reuse guidelines: sagepub.com/journals-permissions DOI: 10.1 I 77/0739456X20984519 journals.sagepub.com/home/jpe

(SAGE

\author{
Mattia Bertin'(1), Vittore Negretto', \\ and Francesco Musco'
}

\begin{abstract}
This paper examines how a town affected by a catastrophe can be restored by repositioning. We describe how we locally applied a method for building back better with participation. To do it, we merged some already known techniques. We learned three lessons. First, the methodology that we deployed can support a nonconflictive recovery process. Second, the building's physical forms for the reconstruction according to the preferences of residents must be deeply investigated before proposing a model. Third, a post-disaster recovery plan has several problems in application, and where possible a pre-disaster recovery plan is preferable.
\end{abstract}

\title{
Keywords
}

catastrophe, repositioning, community building, pre-disaster recovery plan, complexity

\begin{abstract}
Este artículo examina cómo se puede restaurar una ciudad afectada por una catástrofe mediante el reposicionamiento. Describimos cómo aplicamos localmente un método para reconstruir mejor con participación. Para ello fusionamos algunas técnicas ya conocidas. Aprendimos tres lecciones. Primero, la metodología que implementamos puede apoyar un proceso de recuperación no conflictivo. En segundo lugar, las formas físicas del edificio para la reconstrucción según las preferencias de los residentes deben investigarse a fondo antes de proponer un modelo. En tercer lugar, un plan de recuperación posterior a un desastre tiene varios problemas de aplicación y, cuando sea posible, es preferible un plan de recuperación anterior al desastre.
\end{abstract}

\section{Keywords}

catástrofe, reposicionamiento, construcción comunitaria, plan de recuperación previo al desastre, complejidad

摘要

本文研究了如何通过重新定位来恢复受灾害影响的城镇。我们描述了如何在本地应用一种通过参与度更好的方法 进行重建。为此, 我们整合了一些已知的技术。我们吸取了三个经验：首先，我们部署的方法可以支持非冲突恢 复过程。其次, 在提出模型之前, 必须深入研究根据居民的喜好进行建筑物重建的物理形式。第三, 灾后恢复规 划在应用中存在几个问题，并且在可能的情况下，最好使用灾前恢复计划。

矣键词

灾害, 重新定位, 社区建设, 灾前恢复计划, 复杂性

\section{Introduction}

After every disaster, a declaration to rebuild how it was and where it was is the immediate approach to post-disaster recovery. The promise of quick reconstruction in the exact same place and with the exact same characteristics of what the disaster destroyed condemns a community to the probable recurrence of the same tragedy. Disaster managers often realize the need for a total rethinking of forms and
Initial submission, May 2020; revised submissions, July and October 2020; final acceptance, November 2020

'Università luav di Venezia, Venezia, Italy

Corresponding Author:

Mattia Bertin, Università luav di Venezia, Dorsoduro 2196, Venezia 30135, Italy.

Email: mbertin@iuav.it 
relationships of buildings, infrastructures, and settlement requirements, to deal with the recurring post-disaster shocks and future catastrophes, but find themselves in conflict with local communities. Locals, on the other side, view recovery as a return to what was a possession of their lives (Love and Vallance 2013). These are the issues faced by Cascia, a small but representative town, as it recovered from some earthquakes in 2016-2017 that rolled across central Italy.

The case study described in this paper portrays a reconstruction process that could overcome the pre-existing issues in central Italy in 2016. We took examples from the Edward Blakely (2012a) post-disaster reposition notion from his work in New Orleans (Fields, Thomas, and Wagner 2017) fused with tools for local neighborhood quality interpretation. Being the scenario different in history, scale, and planning traditions, we used these reference as guides.

Cascia's council and administration invited the IUAV Planning Climate Change Lab to assist in guiding the community to a new path post-disaster to handle the physical, economic, and social damage of the catastrophe. Our action research commenced immediately after the tremors of October 2016 and lasted until November 2019 in the postdisaster recovery phase. The Iuav team organized citizen participation to rethink the forms of the damaged built environment. The team was composed of three urban planners and supported by an architectural designer. The planners were a professor, a researcher, and a $\mathrm{PhD}$ candidate. The designer was a researcher. All the team is still working together in IUAV University of Venezia. The scope of the job was to develop a new physical design of the first suburbs of Cascia for the reconstruction. It has to be better suited to respond to seismic stresses while increasing sociality and healthy civic as well as an improved landscape quality. The research was really practice oriented and effectively contributed in transforming Cascia changing its buildings and the relation between the inhabitants.

\section{The Case Study}

The Umbria region is in the center of one of the highest seismic risk areas in Europe, with a high-stress seismic event occurring every ten years on average. Umbria contains some of the most famous tourist destinations in the country: Perugia, Assisi, Norcia, and Cascia itself. The territory is mainly hilly, far from the sea, and immersed in the woods of the Apennines. The cities, all small, are characterized by historical centers of the highest quality and are located on top of the hills for ancient reasons of defense. Many of these cities have then expanded from the villages, with low-quality workers' quarters on the slopes of the hills.

The experiences of post-earthquake reconstruction carried out in this place in the last century never questioned the underlying urban forms and textures (Fabietti, Giannino, and Sepe 2013). On a few occasions, structural improvements were made, but these have only related to construction technologies.

The 2016-2017 earthquakes were part of a chain of earthquakes recurring every fifteen to twenty years. The majority of the buildings in the historical center were already reinforced following previous earthquakes, so the greatest new damages were registered in a neighborhood at the edge of the historic center, in a low-lying area where flood deposit soils cause a higher seismic amplification of the ground. This neighborhood is rife with brick buildings of four to five stories from the 1940-1970 era; the buildings represent plain, unappealing building stock and are lacking in well-designed public spaces. This part had a really conflictive relation in terms of landscape with the near historical center. The intervention in recovery could become supporting for heritage valorization of the historical hamlet, removing a constraint between the heritage and its surrounding landscape. About five hundred people used to live in the neighborhood and could no longer return to their homes. Each family had ownership of their apartment, complicating the decision-making process.

\section{Rebuilding or Repositioning?}

The interrelation between the landscape and the inhabitants of the town subject to the disaster is characterized as a traumatic loss of the identity of place (Levine et al. 2005). This feeling expresses a tension between the hope of resurrection through the return to where it was/how it was and the progression toward an unknown future. Regenerative policies should increasingly look for ways to involve the population to respond to the real needs of the injured community (Lewis and Mioch 2005). One way to achieve this is by reducing the scale of intervention, working at the local level. Along the same line, some emergency managers and reconstruction directors are increasingly moving toward a participatory approach (Horney et al. 2016). The recovery choices influence the citizens' identities and lifestyles, and use public space to define individuals' relationship with the environment (Berke et al. 2014; Blakely 2012a; Finn, Chandrasekhar, and Xiao 2019, 3).

Dealing directly with the decisions can also help to overcome the trauma by breaking down the stereotypes linked to the figure of disaster victims. Besides this, active engagement of the local communities is now recognized as part of the rehabilitation process, as a sort of social therapy (Archer and Boonyabancha, 2010; Horney et al. 2016). Personal involvement of those affected by the earthquake produces positive results even years after the event itself, healing the social damage that, unlike the mitigation of physical damage, can persist over a wide time range. Participation is also fundamental as a defensive measure for the social capital represented by the marginal classes, that is, the most vulnerable, who are usually excluded from participatory processes. To avoid this exclusion, it is essential to plan this procedure in the most inclusive way, to also involve those people who 


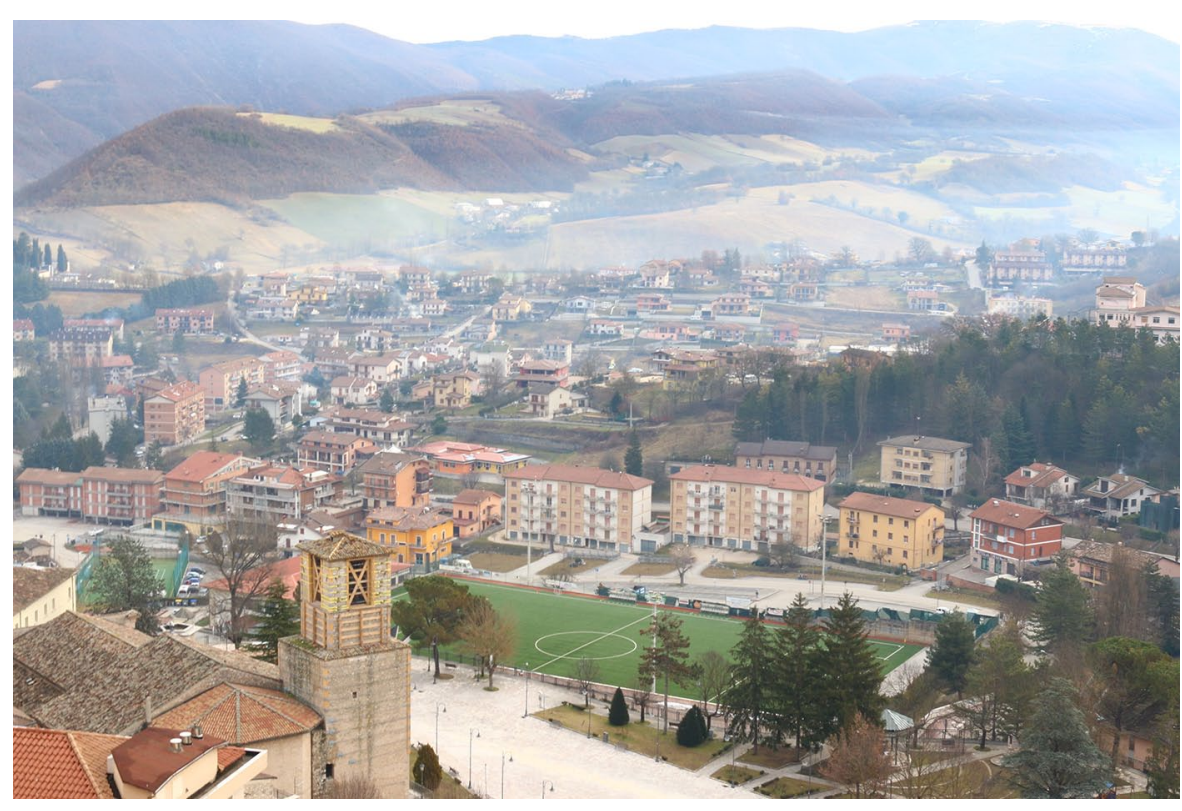

Figure I. Cascia's two natures: the ancient city on the left and the new low-quality suburb facing it. Note: Photo by the authors.

could be skeptical or less represented (see Ahrens and Rudolph 2006, 215)

The community, while facing the trauma brought by the seismic event, must reconsider some aspects taken for granted, formulating a new hierarchy of priorities of the model of living, and redesigning the urban and relational form of its territory. The inhabitants may have to recognize new needs and demand new standards, sometimes far from the pre-disaster living conditions.

"To strive for resiliency entails building back to be safer, healthier, and more equitable, and better able to absorb, recover from, and successfully adapt to future adverse events" (Berke et al. 2014, 310; Peacock et al. 2008; Smith 2011; Smith and Wenger 2006).

The reconstruction of the community is therefore a fundamental requirement for the success of the reconstruction itself, to avoid the risk of rebuilding cities that will have no inhabitants to occupy them (Berke, Song, and Stevens 2009; Chandrasekhar, Zhang, and Xiao 2014).

Our method took advantage of this already consolidated knowledge to orient the process. To do this, we took two case studies as drivers. The first was the experience of New Orleans post-Katrina recovery (Blakely, 2012b; Fields, Thomas, and Wagner 2017; March, Kornakova, and Leon 2017).

Here we look at planning through the prisms of contestants, who use it as a vehicle to gain recognition, shape debates, and move their agendas, and how they understand the meaning and opportunities for plans to garner a position for themselves. So, planning and planning tools can shape the future of New Orleans in ways that residents never anticipated. (Blakely 2012b, 121)

The intuition applied in New Orleans has been to proceed along a path of regeneration that questions the social deficiencies and economic prospects of an affected territory, considering the event, according to Žižek, as an irrecoverable change (Finn, Chandrasekhar, and Xiao 2019, 10; Žižek 2014, 22). The aim was to save the spirit of the place by working with the community to reshape its social and physical form and not try to regenerate the past but reposition a vision of a better, more inclusive social and physical future (Finn, Chandrasekhar, and Xiao 2019, 114; Schwab et al. 2003).

According to Olshansky et al. (2008), in Longer View: Planning for the Rebuilding of New Orleans, and trying to learn the lesson of Vale and Campanella (2005) about the possibility of making a city more resilient after reconstruction, we considered it fundamental to not fall into the risk of "where it was, how it was": "a recovered urban system's resilience may be weakened if it is too similar to its predecessor, making it more vulnerable when a similar disaster hits in the future" (Olshansky et al. 2008, 281).

The second resource we considered was from Kartez and Lindell (1987) in Planning for Uncertainty: The Case of Local Disaster Planning. From Kartez and Lindell, we tried to understand the value of uncertainty in local recovery planning to design the capability of the plan to deal with a future disaster scenario, in which it is necessary to repair the social fabric, a lesson learned from the failure of past experiences. 


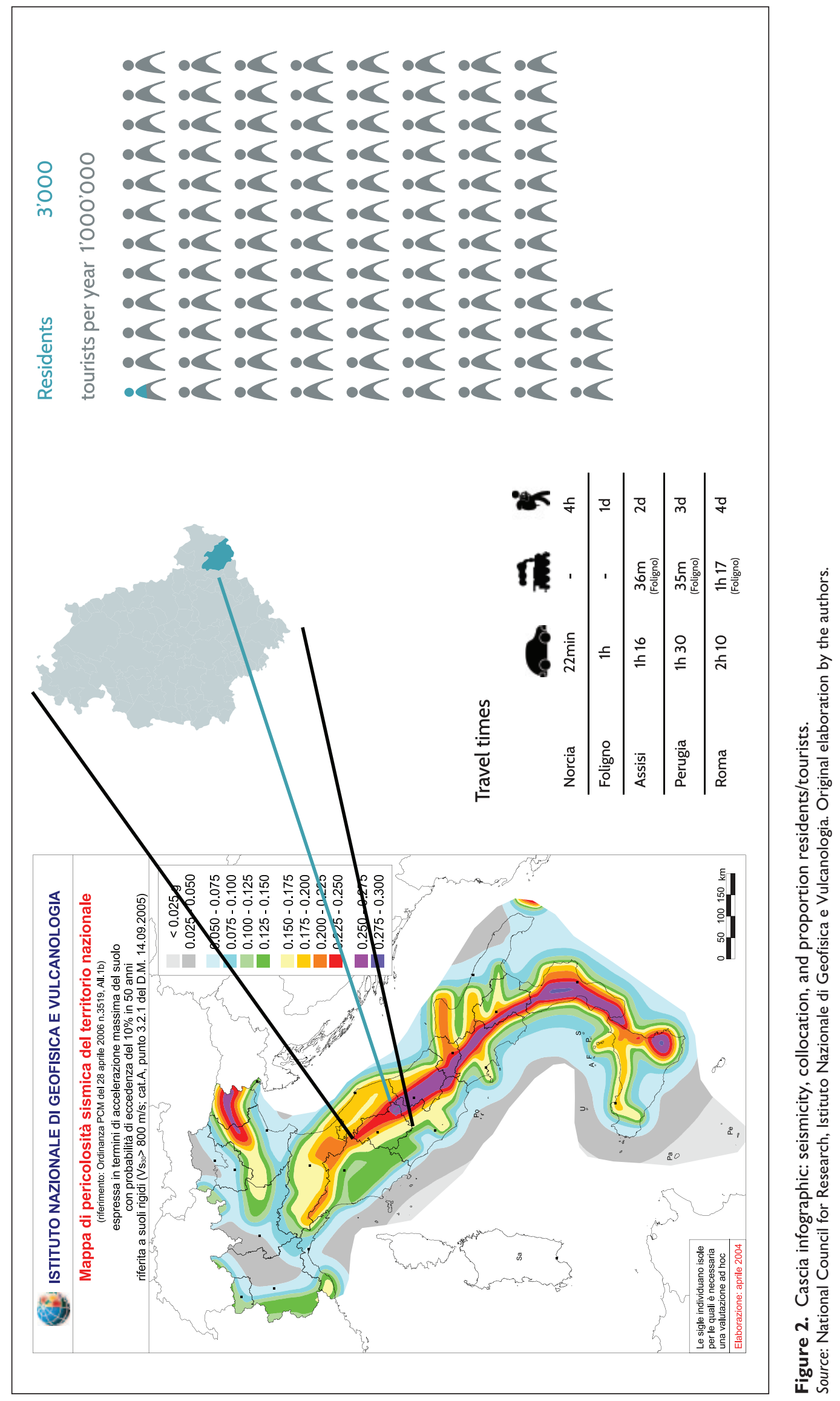




\section{A Repositioning Approach through Consensus}

After an event, there is the risk of a community to suffer a second more creeping damage: the compulsion to replicate the previous dangerous system, physically and socially inadequate (see Lindell 2013). Therefore, we acted to take advantage of the complete change of the world perceived as trauma and opportunity (see Žižek 2014, 10, 20).

We considered the need to involve citizens in the definition of the values for regeneration, aware that "the process of physical reconstruction is necessary, but, on its own, it is not a sufficient condition to enable a restart. That the city is much more than its buildings; there needs to be a new shared destiny (re-positioning)" (Blakely 2012b, 104-106; Vale and Campanella 2005).

As we can see in Figure 3, we tried to organize the planning process on a seven-step methodology supported by consolidated literature to realize a replicable and evaluable case study.

The main goal of the project was to offer a comprehensive and integrated vision of Cascia's post-disaster planning process, which can be replicated in other situations. To strengthen the current and future resilience of the area, it is imperative that the whole process encompass a community-based approach, population preparedness, and development of adaptive capacity, all of which are discussed below.

In this sense, we tried to make European the New Orleans experience, applying it to a little city with high heritage assets density and relevant social cohesion.

The method has been structured in seven steps: define the scope of the impact, investigate the quality of the injured neighborhoods, evaluate the constraints, discuss the driving values with the communities, design a proposal, discuss the proposal with the community, and consolidate the proposal. The administration approved the intent to apply this method, with the aim of strengthening the center of Cascia socially and aesthetically, and involving the community in this process (see Medd and Marvin 2005, 43-46).

\section{Define the Scope of the Impact}

The first step was suggested by Daniel Brown, Stephen Platt, and John Bevington's Disaster Recovery Indicators: Guidelines for Monitoring and Evaluation (Brown, Platt, and Bevington 2010, 77-78). To do this, we collected in a GIS map the data on the condition of the buildings, the effects of the impact, the type of buildings, the economic activities, the stakeholders, and the families living there.

In this first step, we mapped the urban fabrics of the intervention area and analyzed them. We established a case file on each of the thirty-nine units set for demolition and built a data set. The data set included use (prevailing uses; ground floor use), typology (surface area; morphology; materials; roof typology; subsequent additions; number of visible floors; presence/absence of fences), state (conservation; visible damages), and services (parking lots along the road; interventions for energy efficiency; private/shared/public garden). All this information was collected in a database that has been accessed throughout the whole design and participatory process. This database provided the knowledge to evaluate the form, dimension, and position of the purposed redesign.

\section{Investigate the Quality of the Damaged Neighborhoods}

We considered as an efficient path the possibility to integrate it with the local perception of the injured area. So the next step has been the investigation of the perceived quality of urban spaces before the earthquake to recognize the social imprint in the formal models to be applied (Stanley 2017; Xiao et al. 2018). To organize this step, we were inspired by the research done by Fornara, Bonaiuto, and Bonness in Perceived Urban Residential Quality Indicators. From their handbook, we selected a series of indicators on urban quality perceived as a base to discuss with citizens the formal limits that existed in the neighborhood that was the subject of the intervention (Fornara, Bonaiuto, and Bonnes 2010). The participatory technique we applied had the form of the consensus method (Giovanni 2011; Zammuner 2003) on four thematic cores, and this was undertaken in two sessions. The indicators proposed by Fornara et al. (2010) were collected in four categories to encourage discussion: vegetation and services, road conditions, housing, and urban shape.

The survey was realized by the IUAV team. We made four site visits to complete this analysis, using a geo-referenced evaluation tool. We built an investigative rubric that we compiled for every block. The result showed the area to be characterized by a very low-quality building aesthetic that was poor in collective usability and had a lack of commerce (just a couple of shops). The streets appeared over-dimensioned, especially the internal ones. We noticed that the forms of the community fabric suggested an absence of collective cooperation and rarefied neighborhood life, in strong contrast with the rest of the town.

\section{Evaluate the Constraints}

At this point, we added to this overlapping of cognitive levels all the constraints that should guide our proposal, both by law and by physical condition. We took into account first of all the seismic microzonation that informed us about the specific danger of the project area, delineating the places where reconstruction is not recommended to avoid new heavy impacts from future seismic events (Highfield, Peacock, and Van Zandt 2014). We also took into account hydraulic and hydrogeological risks to avoid rebuilding in areas potentially at risk, especially in a climate change scenario. We also noted 


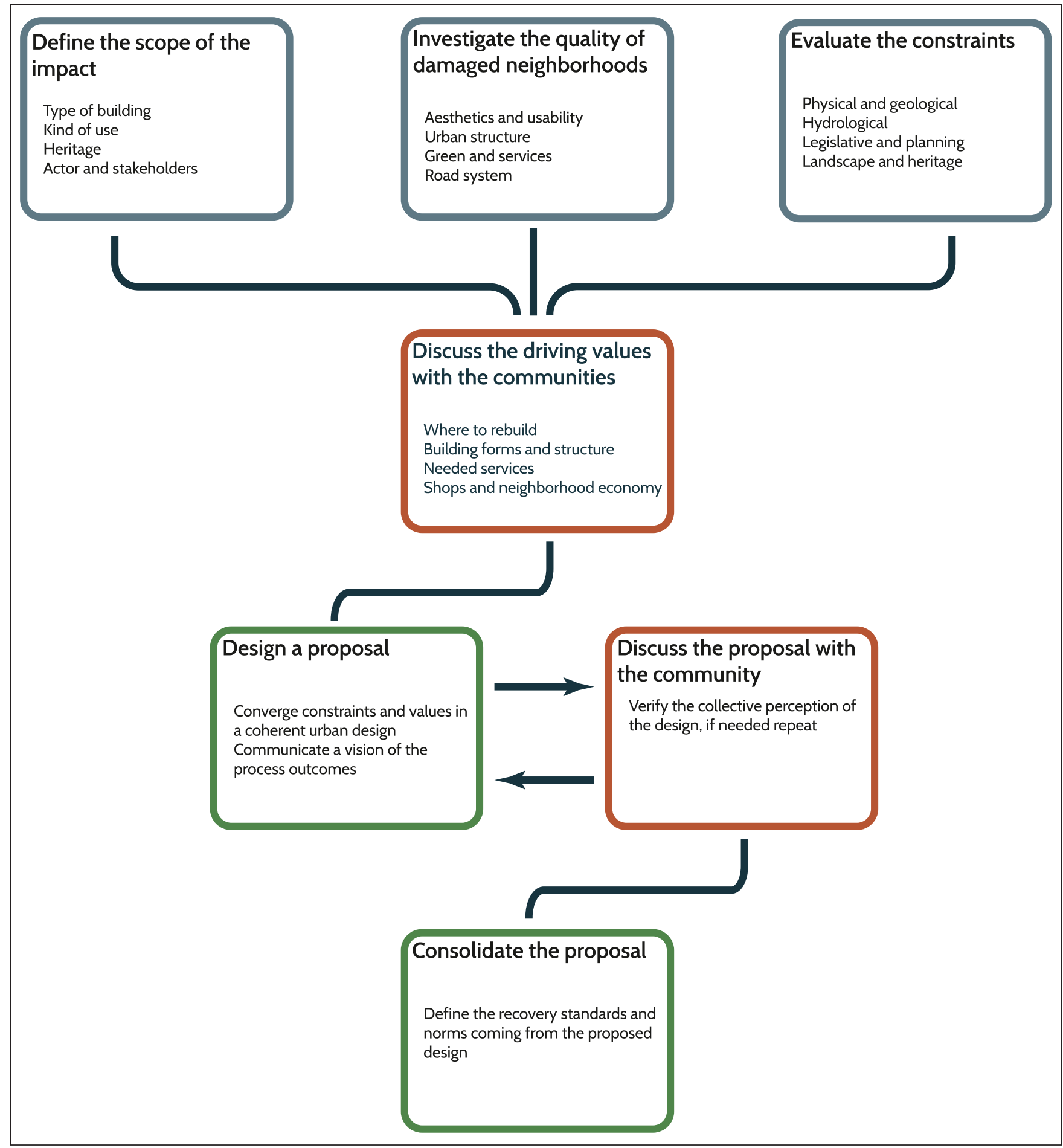

Figure 3. Reconstruction scheme: A conceptual map of the methodology and steps considered for constructing the project proposal. Note: Scheme by the authors.

the constraints and prohibitions arising from existing plans and national regulations on rebuilding and land use. Finally, we considered the landscape and the important heritage value of the territory, trying to redevelop the fabric that existed before the construction of the neighborhood, to enhance the village and its memory and artistic value. These elements allowed us to exclude alternative design paths and to orient us toward a proposal that would be consistent with the territory from the point of view of risk, landscape, and norms (Berke, Song, and Stevens 2009). 


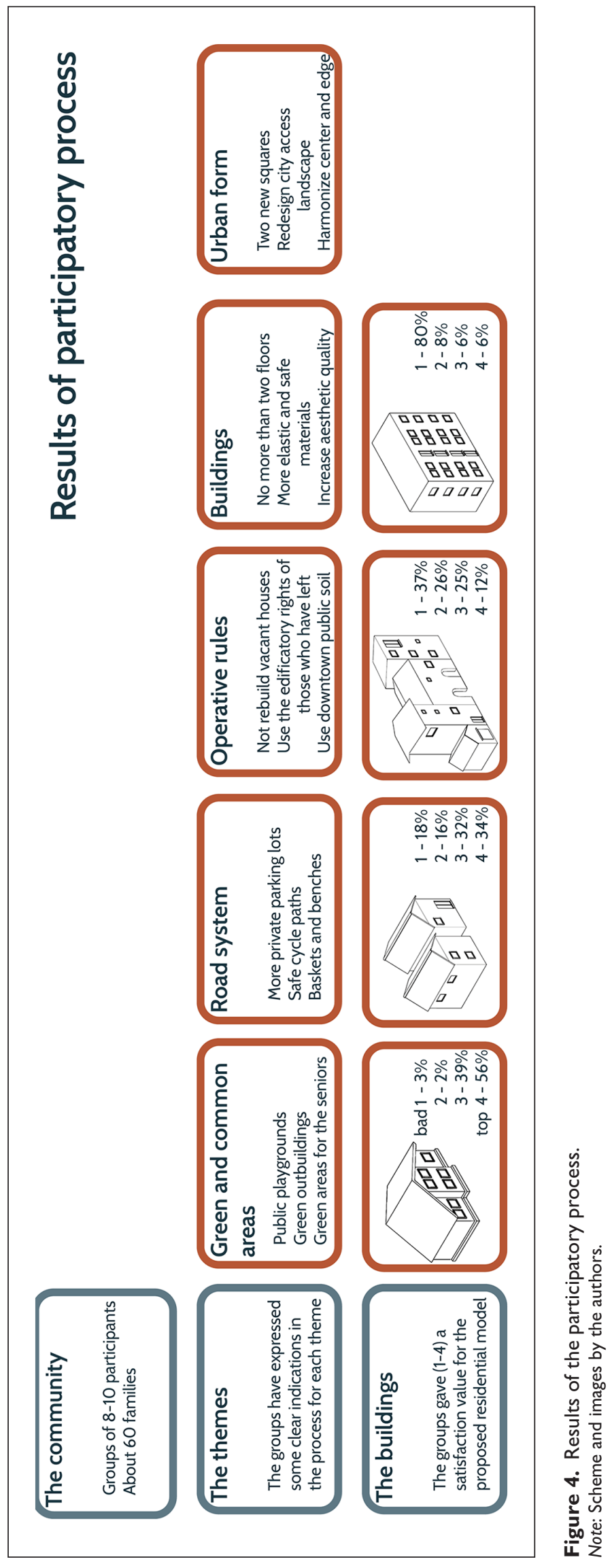


We could recognize some relevant constraints. The injured neighborhood had been built on really dangerous river deposition material. This makes it a surface of seismic acceleration, which, in an area of frequent earthquakes, is acceptable neither by normative standards nor by common sense. A second constraint was related to the local plan: we had to decide where to displace or redesign the injured fabric, choosing among few possible areas, and we had no time to replan the public areas. On the hydrological side, the useful areas were deemed to be safe, so this was not a relevant theme. The last constraint came from the requirements for accessing the national funding for reconstruction: it was required to rebuild at most the same number of building.

\section{Discuss the Driving Values with the Communities}

This step was dedicated to investigating the preferences about urban services and housing typology for the rebuilding phase. We considered that we had to share with the community the values able to drive the design of the regeneration, before applying them. To do this, we organized another session of the same focus groups and used two different techniques. First, we discussed with the focus groups the establishment of a goal to be achieved for every indicator group. Second, with every focus group, we distributed a questionnaire on house typology, asking participants to choose the favorite ones. We then used these questionnaires to discuss the form preferences, applying a consensus method, recognizing step by step the favorite elements to be preferred in the reconstruction. In following this step, we were sure to have reached a shared system of values able to orient the design process.

The fourth step involved the injured community, about sixty families, in focus groups to discuss their perception of the quality of their neighborhood. The facilitators encouraged debate on the four themes previously described and, following an explicit need that arose, added a fifth theme dedicated to operative proposals. This step took place in two sessions. The first was organized through several meetings in the same week for groups of eight to ten residents. This session was dedicated to producing a shared perception of the necessary and desired quality to orient the proposal and to deepen the knowledge gained from the data previously collected. The consensus method guided the debate in an open form, one theme at a time, allowing for the sharing of a common vision and the building of constellations of interests and problems. Then the common vision was surveyed through a questionnaire completed on the spot and discussed collectively. This was also dedicated to individuating physical typologies of houses considered valuable by citizens. These two sessions led to coherent indications used for the drafting of the first reconstruction proposal. What emerged was strong support for a redesign of the neighborhood on models of one or two floors disposed around courtyards.

\section{Design a Proposal}

The fifth step was dedicated to the design work. Following the leadership of the architectural designer of the team, we redesigned every building of the injured neighborhood, proposing forms and volumes able to respect the indications coming from the previous steps. The aim here was not to create an executive project, but to realize some maps and volumetric plans that could be discussed by the community.

The initial project proposal was designed considering all the inputs of the four previous steps. The main drivers in the design part were the indications received and the suggested preferences previously discussed with the community. The design choices had taken into account the seismic microzonation map and other multi-risk maps, the planned expansion area and other planning documents of the local authorities, and the laws regarding earthquake in central Italy promulgated by regional and national authorities. We defined eight blocks of one to two floors, which sometimes follow the preexisting lots and sometimes include the new empty public areas able to be built on.

The proposal brought innovation to the housing typology and at the same time fulfilled the technical requirement of not splitting the buildings, so as not to lose the funding provided for reconstruction. This was reached through the composition of primary forms joined together in a linear typology but with high independence (Figure 5). These special joints between the elements were designed to avoid construction techniques that would be vulnerable to seismic risk. We finally produced an illustrative rendering of every new block, to make it easier for the results to be discussed publicly in the sixth step (Figure 6).

\section{Discuss the Proposal with the Community}

We organized another participative session with the community, dedicated to evaluating and redesigning the project's purpose and scope, taking public opinion and agreement into account. Repetitive steps were necessary until maximum public support was achieved.

The proposal was then discussed on January 19, 2019, in a joint session with the community, the local authorities, and the architects and engineers appointed by the owners to lead the residential building process. Concerns were expressed about suggestions that led to a revision of the proposal, which was presented on February 4, 2019. The most relevant concerns were about the orientation of some blocks in relation to the landscape, to not lose the view for the inhabitants who had previously been living in the higher flats. The outcome of this recursive process can be seen in the rebuilding and repositioning plan in Figure 7.

\section{Consolidate the Proposal}

As stated in the fifth step, our goal was to design a strategic masterplan. We started from the approved purpose and used 

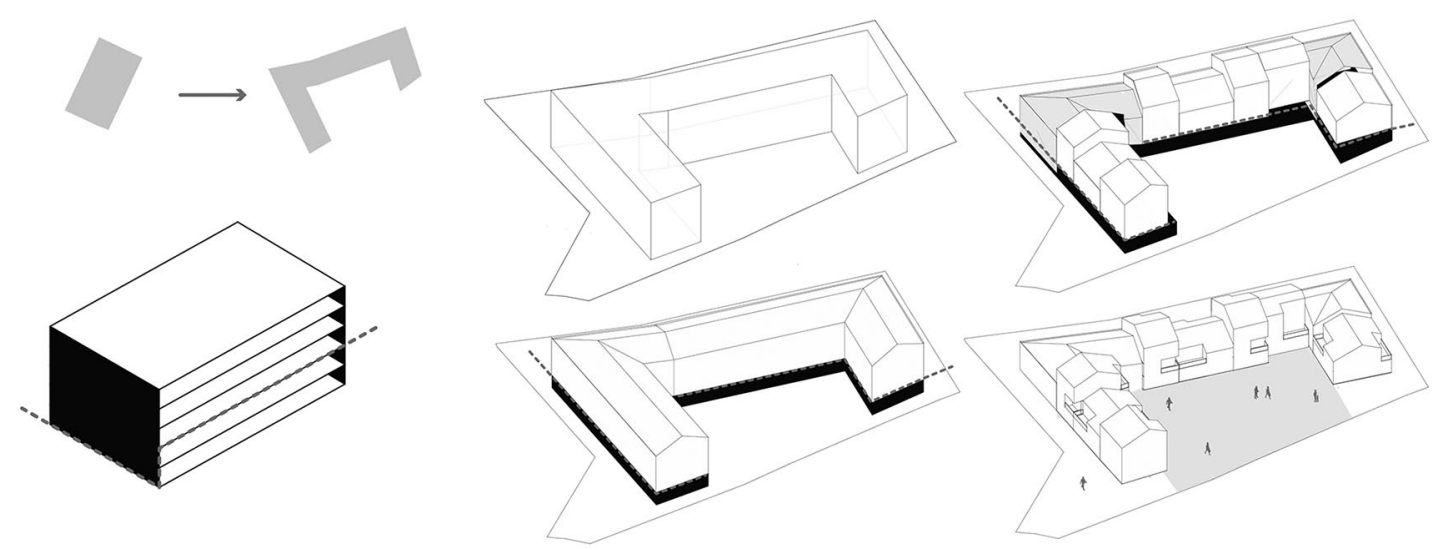

Figure 5. Descriptive diagram of the design process to deconstruct the monolithic bloc into a linear typology of independent volumes of increased urban quality.

Note: Particle 455, construction years 1976-198I. Total surface area: I’310 $\mathrm{m}^{2}$ (grounding only). Image by the authors.

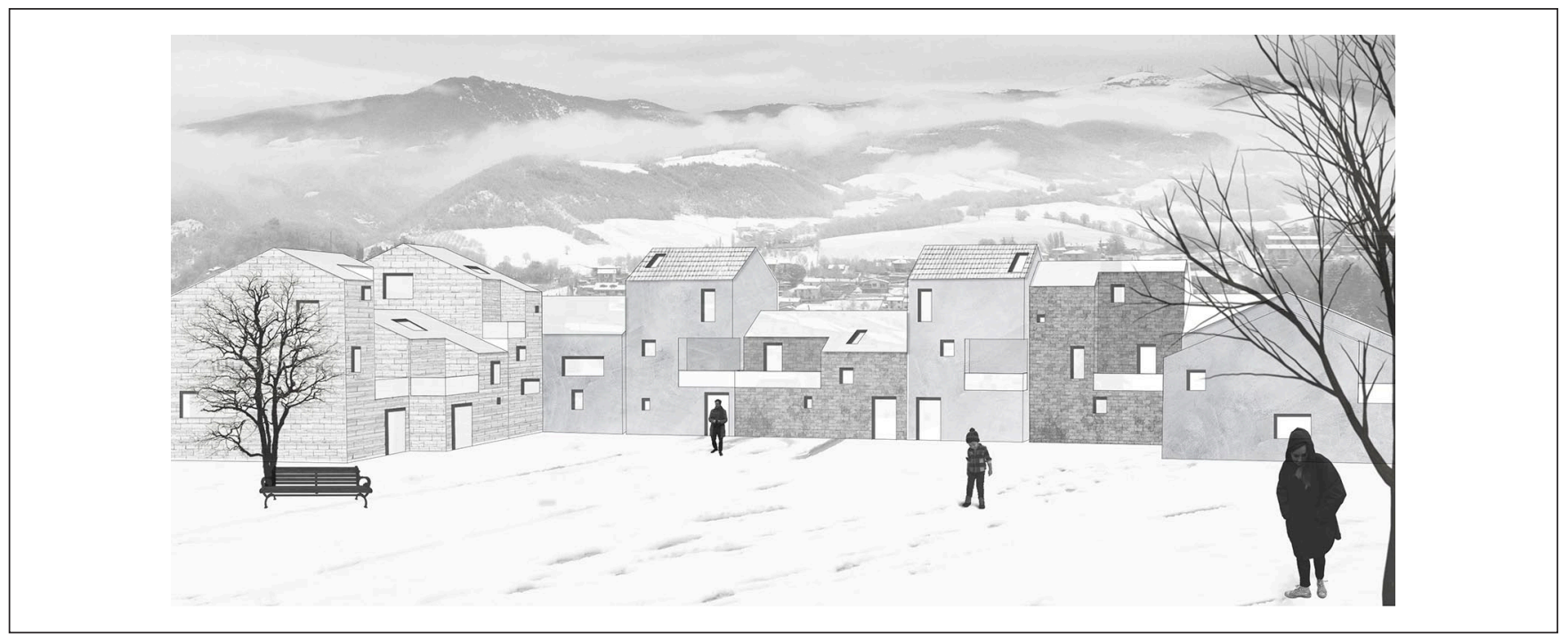

Figure 6. A vision of the design proposal for the joint session with community and local stakeholders.

Note: The drawing highlights some of the preferences expressed by the community: Shared gardens and variable volumes, setbacks, and numbers of floors. Image by the authors.

this to define the rules for the regeneration of the single buildings. Thus, the final result of this method was a group of norms and an example of their application, but allowing the freedom for individual owners to apply the norms in different ways with their private designers.

Once the masterplan was discussed and had achieved a strong consensus, we translated it into technical standards capable of responding to legislative requirements, to the vision of the administration, and to the needs of the community. The set of repositioning approaches drafted in the previous steps had to find a direct implementation in the local planning documents, in design guidelines, and in agreements for funding applications. Only through this last step could this coproduced community vision for repositioning be translated into an implementation process. We decided to use our proposal just as an orienting suggestion, able to give relative freedom in design to the architects and planners who had to conceive and apply the projects.

The final result was a collection of norms and the master plan, accompanied by elaborated volumetric renderings and views. The norms were dedicated to fix the relations between highness, deepness, and largeness, so to provide a little number of possible alternatives in private executive design, avoiding the distortion of the plan in the implementation phase.

\section{Lessons Learned}

In this research, we learned three lessons, two confirmative and one ameliorative, for the process we developed. 


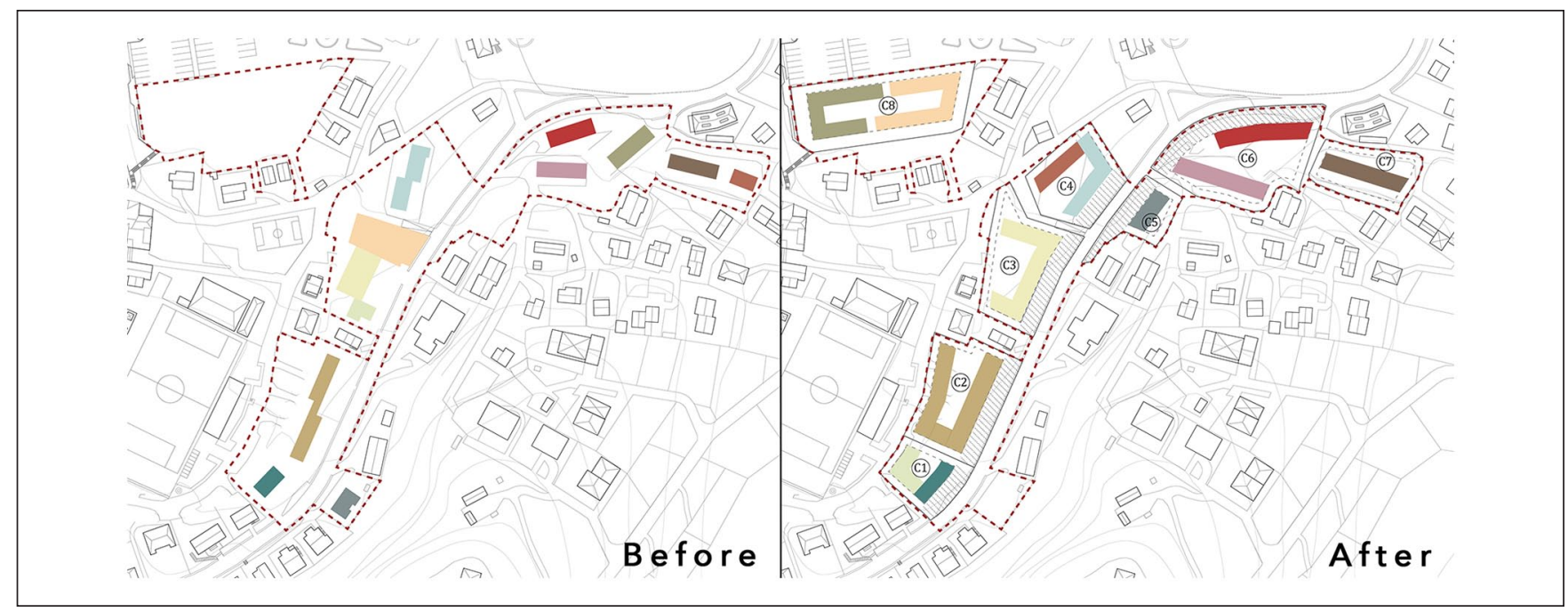

Figure 7. Comparison between the original distribution of the neighborhood before the earthquake (left) and the rebuilding and repositioning plan (right).

Note: Each redesigned linear unit on the right corresponds to an original bloc unit on the left. Color coding of the buildings helps to identify this correspondence. Image by the authors.

- The methodology has been able to support a peaceful recovery process. The application of the selected and consolidated techniques has been a success.

- The physical forms for the reconstruction of buildings, according to residents' desires, must be deeply investigated before proposing a model.

- The post-disaster recovery plan had several problems in its application, and could be preferred to develop a pre-disaster recovery plan where possible.

The first lesson learned was a confirmation of the methodology as a tool that was able to help in post-disaster reconstruction. The consolidated methodology presented here was effective on three different levels and generally seems to be a useful framework.

First, the methodology has been useful in managing the conflicts in the recovery phase. The plan was embraced by the population and the administration, and it was the only document which found general support from a majority within the city council. Past reconstruction experiences in Italy have led to conflicts that can last for decades (e.g., the L'Aquila earthquake of 2009). The approach here kept the community and the administration together by the creation of a shared interpretation of the territory and by a sense of urgency. The consensus approach and the discussion of orienting values were an effective path for avoiding a postemergence impasse.

Second, the process led to a better understanding for the planners and for the local community of the formal opportunities and the citizens' wishes for their neighborhood. Starting with a survey of values and constraints helped to keep the discussion out of the dichotomy between where it was/how it was and innovation.
Third, the research-by-design approach applied in the planning phase has been really effective in dealing with the local community, avoiding a discussion over standards or aims that could have been misunderstood without such representation.

Fourth, we can confirm that the approach applied in New Orleans can be translated to Europe, or at least in Italy. Considering the big differences in setting, we could replicate this approach as a driver to define a methodology able to deal with a disaster in a really different context. To do this, the consolidation of an organized system of values that took into account the local situation, here provided by the indicators of Fornara et al., proved successful. In addition, we can say that the consensus method worked as the right technique for creating a participative path. We suggest the replication of the methodology we tested on other similar occasions to further test its effectiveness in producing a shared plan.

The second lesson came from the desires collected through community preferences on housing typology. The chosen models pointed us to the adoption of a brand new template that accommodated the wishes of the users while increasing resilient capacity to seismic impacts. The total rejection of the condominium block typology by the community residents taught us that residents desire a relationship between their community and the public space, preferring an aggregation of units resulting in greater suitability to the landscape, thus enhancing the area's visual presentation as a city entryway. The decision to use this typology (Figures 5 and 6) also stemmed from the study of the settlement morphology of the historical fabric, which showed aggregations in rows of up to three floors in height, such as those that were proposed. 
The third lesson came from the application after the planning phase. The administration had several problems in completely applying the resulting plan. According to Italian law, if just one of the building owners opposes a transformation, this transformation must be avoided, and a great majority of residents must be in favor. A minority of families were concerned about the necessary time to complete the project and feared that something would go wrong; they preferred to rebuild the buildings with the same low quality, but which they considered more likely to be built. The compromise was to redesign just some buildings, those in which every family agreed with the changes.

We identified three causes for this gap between the process and application of the results.

The first is the time that passed from the earthquake to the intervention, and from the total exhaustion of the population consumed with post-event planning. This period may have affected the desire of the community for a restart and created a sense of disorientation. This confirms for us the importance of involving the communities before, during, and after a catastrophe (Blakely 2012b, 125; Ganapati and Ganapati 2008, 55; Lewis and Mioch 2005, 51).

The second cause is that the promise of rapid reconstruction generated an unrealizable desire. The desire was to remove a traumatic event by returning to a broken past. The third element is the unpreparedness of the European systems for reconstruction planning. This could be the most interesting and unexpected finding of the research. In Italy, and generally in Europe, recovery is not governed by a general system of rules and planning that began before the disaster. Each recovery is planned and organized anew, every time, by ex-post ad hoc rules and plans.

Something that we can learn from this research is a new research question: do we need a pre-disaster recovery plan? The U.S. experience in pre-disaster recovery planning, indicated by the paper by Berke and colleagues on "Adaptive Planning for Disaster Recovery and Resiliency," could perhaps help in anticipating the social and psychological barriers that make it so difficult to produce an effective post-event intervention in Europe. Berke and his team affirm that "a pre-disaster recovery plan that considers how a community should be redeveloped is a logical first step to support resiliency during high uncertainty and rapid change" (Berke et al. 2014, 210; Woodruff et al. 2018, 2, 9). Having a strongly supported plan that has been previously discussed with the community and approved without the immediate anxiety caused by a disastrous event could help the community to have a clear route for post-event application, avoiding some of the difficulties we found. It could also help political bodies in promising something that is actually achievable, avoiding the problem of how it was/where it was rebuilding. Developing tools like this in advance can not only ensure a better performance in plan application but moreover can help the community "to be safer, healthier, and more equitable, and better able to absorb, recover from, and successfully adapt to future adverse events" (Berke et al. 2014, 310; Peacock et al. 2008; Smith 2011; Smith and Wenger 2006).

\section{Conclusion}

The research achieved three goals. First, it confirmed the hypothesis demonstrating that participative recovery planning based on the concept of repositioning can efficiently work in post-disaster reconstruction in Europe. Second, in applying the consensus method, we could achieve full support for the plan, anticipating the conflicts. Third, in applying a complexity framework, we could produce a better urban fabric on different levels, providing a higher quality design and a more resilient neighborhood.

We can assume that a process like this can be replicated as a driver for post-disaster recovery in other major disasters in Europe, providing an operative tool in effective post-disaster experiences.

Despite this, it was possible to only partially apply the plan that resulted from the research. We can recognize some important findings from this. The most important is that recovery may have to be anticipated before the disaster on the model of pre-disaster recovery planning. This solution can reduce the risk of having to decide between fast, lowquality rebuilding of the previous situation and slower, high-quality rethinking.

This hypothesis can be explored with dedicated research studies and practices in collaboration with the most exposed cities in Europe, starting from already existing maps of danger and vulnerability.

\section{Declaration of Conflicting Interests}

The author(s) declared no potential conflicts of interest with respect to the research, authorship, and/or publication of this article.

\section{Funding}

The author(s) disclosed receipt of the following financial support for the research, authorship, and/or publication of this article: This work was supported by Sara D'Annunzio, who helped in the fieldwork, in the preparation of focus groups, and in the realization of some of the graphic materials. This work was also supported by Professors Alberto Ferlenga, Benno Albrecht, and Domenico Patassini, who have patiently and acutely engaged in continuous debate and review on this research. Finally, we have to totally express our gratitude to Prof. Edward Blakely for his lessons, his support, and the continuous exchanges of views without which we would not have been able to take this step.

\section{ORCID iD}

Mattia Bertin (iD https://orcid.org/0000-0003-1342-8359

\section{References}

Ahrens, Joachim, and Patrick M. Rudolph. 2006. "The Importance of Governance in Risk Reduction and Disaster Management." 
Journal of Contingencies and Crisis Management 14(4): 207-20.

Archer, Diane, and Somsook Boonyabancha. 2010. "See a Disaster as an Opportunity-Harnessing the Energy of Disaster Survivors for Change." In AA.VV. Global Assessment Report on Disaster Risk Reduction. London: United Nations Publication.

Berke, Philip R., John Cooper, Meghan Aminto, Shannon Grabich, and Jennifer Horney. 2014. "Adaptive Planning for Disaster Recovery and Resiliency: An Evaluation of 87 Local Recovery Plans in Eight States." Journal of the American Planning Association 804:310-23. doi:10.1080/01944363.2 014.976585 .

Berke, Philip R., Yan Song, and Mark Stevens. 2009. "Integrating Hazard Mitigation into New Urban and Conventional Developments." Journal of Planning Education and Research 28(4): 441-55.

Blakely, Edward. 2012a. My Storm. Managing the Recovery of New Orleans in the Wake of Katrina. Philadelphia: University of Pennsylvania Press.

Blakely, Edward. 2012b. "Recovery of the Soul: Rebuilding Planning in Post-Katrina New Orleans." Housing Policy Debate 22(1): 117-31.

Brown, Daniel, Stephen Platt, and John Bevington. 2010. Disaster Recovery Indicators: Guidelines for Monitoring and Evaluation. Cambridge: Cambridge University Centre for Risk in the Built Environment.

Chandrasekhar, Divya, Yang Zhang, and Yu Xiao. 2014. "Nontraditional Participation in Disaster Recovery Planning: Cases from China, India, and the United States." Journal of the American Planning Association 80(4): 373-84. doi:10.1080/0 1944363.2014.989399.

Fabietti, Valter, Carmela Giannino, and Marichela Sepe. 2013. "La ricostruzione dopo una catastrofe: da spazio in attesa a spazio pubblico [Reconstruction after a disaster: From waiting space to public space]." Urbanistica Dossier Online $5: 2-4$.

Fields, Billy, Jeffrey Thomas, and Jacob A. Wagner. 2017. "Living with Water in the Era of Climate Change: Lessons from the Lafitte Greenway in Post-Katrina New Orleans." Journal of Planning Education and Research 37(3): 309-21.

Finn, Donovan, Divya Chandrasekhar, and Yu Xiao. 2019. “A Region Recovers: Planning for Resilience after Superstorm Sandy." Journal of Planning Education and Research. July 2019. doi:10.1177/0739456X19864145.

Fornara, Ferdinando, Marino Bonaiuto, and Mirilia Bonnes. 2010. Indicatori di qualità urbana residenziale percepita (IQURP). Manuale d'uso di scale psicometriche per scopi di ricerca e applicativi. Milan: FrancoAngeli.

Ganapati, Emel N., and Sukumar Ganapati. 2008. "Enabling Participatory Planning after Disasters: A Case Study of the World Bank's Housing Reconstruction in Turkey." Journal of the American Planning Association 75(1): 41-59. doi:10.1080/01944360802546254.

Giovanni, Bertin. 2011. Con-sensus Method: Social Research and Construction of Meaning. Milan: FrancoAngeli.

Highfield, Wesley E., Walter Gillis Peacock, and Shannon Van Zandt. 2014. "Mitigation Planning: Why Hazard Exposure, Structural Vulnerability, and Social Vulnerability Matter." Journal of Planning Education and Research 34(3): 287-300.
Horney, Jennifer, Mai Nguyen, David Salvesen, Olivia Tomasco, and Philip Berke. 2016. "Engaging the Public in Planning for Disaster Recovery." International Journal of Disaster Risk Reduction 17:33-37.

Kartez, Jack D., and Michael K. Lindell. 1987. "Planning for Uncertainty: The Case of Local Disaster Planning." Journal of the American Planning Association 53(4): 487-98. doi:10.1080 /01944368708977138.

Levine, Mark, Amy Prosser, David Evans, and Stephen Reicher. 2005. "Identity and Emergency Intervention: How Social Group Membership and Inclusiveness of Group Boundaries Shape Helping Behavior." Personality and Social Psychology Bulletin 31(4): 443-53. doi:10.1177/01461672 04271651.

Lewis, Dan, and Jaana Mioch. 2005. "Urban Vulnerability and Good Governance." Journal of Contingencies and Crisis Management 13(2): 50-53.

Lindell, Michael K. 2013. "Recovery and Reconstruction after Disaster." In Encyclopedia of Natural Hazards, edited by Peter T. Bobrowsky, 812-823. Heidelberg: Springer Netherlands.

Love, Robert, and Suzanne Vallance. 2013. "The Role of Communities in Post-disaster Recovery Planning: A Diamond Harbour Case Study." Lincoln Planning Review 5(1): 3-9.

March, Alan, Maria Kornakova, and Jorge Leon. 2017. "Integration and Collective Action: Studies of Urban Planning and Recovery after Disasters." In Urban Planning for Disaster Recovery, edited by Alan March and Maria Kornakova, 1-12. Amsterdam: Butterworth-Heinemann.

Medd, Will, and Marvin Marvin. 2005. "From the Politics of Urgency to the Governance of Preparedness: A Research Agenda on Urban Vulnerability." Journal of Contingencies and Crisis Management 13(2): 44-49.

Olshansky, Robert B., Laurie A. Johnson, Jedidiah Horne, and Brendan Nee. 2008. "Longer View: Planning for the Rebuilding of New Orleans." Journal of the American Planning Association 74(3): 273-87. doi:10.1080/019443 60802140835.

Peacock, Walter Gillis, Howard Kunreuther, William H. Hooke, Susan L. Cutter, Stephanie E. Chang, and Phillip R. Berke. 2008. "Toward a Resiliency and Vulnerability Observatory Network: RAVON (Report \#08-02R)." College Station: Hazard Reduction and Recovery Center.

Schwab, James, Kenneth C. Topping, Charles C. Eadie, Robert E. Deyle, and Richard A. Smith. 2003. "Planning for the PostDisaster Recovery and Reconstruction." Planning Advisory Service Report (483/484). Chicago: American Planning Association.

Smith, Gavin. 2011. Planning for Post-disaster Recovery: A Review of the United States Disaster Assistance Framework. Washington, DC: Island Press.

Smith, Gavin, and D. Wenger. 2006. "Sustainable Disaster Recovery: Operationalizing an Existing Agenda." In Handbook of Disaster Research, edited by H. Rodriguez, E. L. Quarantelli, and R. R. Dynes. Springer. doi:10.1007/978-0387-32353-4_14.

Stanley, Janet. 2017. "Equity in Recovery." In Urban Planning for Disaster Recovery, edited by A. March and M. Kornakova, 31-45. Amsterdam: Butterworth-Heinemann. 
Vale, Lawrence, and Thomas J. Campanella. 2005. The Resilient City: How Modern Cities Recover from Disaster. Oxford: Oxford University Press.

Woodruff, Sierra C., Sara Meerow, M. Stults, and Chandler Wilkins. 2018. "Adaptation to Resilience Planning: Alternative Pathways to Prepare for Climate Change." Journal of Planning Education and Research. October 2018. doi:10.1177/07394 $56 \mathrm{X} 18801057$.

Xiao, Yu., Kai Wu, Donovan Finn, and Divya Chandrasekhar. 2018. "Community Businesses as Social Units in Post-disaster Recovery." Journal of Planning Education and Research. Published electronically October 6. doi:10.1177/0739456X 18804328.

Zammuner, Vanda Lucia. 2003. I Focus Group. Milan: Società Editrice Il Mulino.

Žižek, Slavoj. 2014. Event. Novara: DeAgostini.

\section{Author Biographies}

Mattia Bertin is a senior researcher at EPiC - Earth and Polis Research Centre, Università Iuav di Venezia. He is a researcher in the field of urban planning and design, mainly concerned with complex urban issues, linked to climate change, disaster, and marginality.

Vittore Negretto is a $\mathrm{PhD}$ Candidate at EPiC - Earth and Polis Research Centre, Università Iuav di Venezia. He is mainly interested in adaptation and recovery planning in complex environments.

Francesco Musco is full professor, director of EPiC-Earth and Polis Research Centre, Università Iuav di Venezia. He is mainly interested in urban planning and sustainability issues, urban regeneration, policy design, urban resilience, climate change, and mitigation and adaptation strategies. 